\title{
3DCT Morphometric Analysis of Sella Turcica in Iraqi Population
}

\author{
Haider Ali Hasan ${ }^{1,2)}$, Mohammad Khursheed Alam ${ }^{3)}$, Yap Johari Abdullah', Junzaburo Nakano ${ }^{5)}$ \\ Tatsunori Yusa ${ }^{5)}$, Asilah Yusof ${ }^{6}$ and Naoto Osuga ${ }^{5)}$ \\ 1) Oral and Maxillofacial Surgery Department, School of Dental Science, Universiti Sains Malaysia, Kelantan, Malaysia \\ 2) Oral and Maxillofacial Surgery Department, Babylon University College of Dentistry, Babylon, Iraq \\ 3) Orthodontic Unit, School of Dental Science, Universiti Sains Malaysia, Kelantan, Malaysia \\ 4) Research and Innovation Unit, School of Dental Science, Universiti Sains Malaysia, Kelantan, Malaysia \\ 5) Department of Pediatric Dentistry, Matsumoto Dental University School of Dentistry, Shiojiri, Japan \\ 6) Craniofacial Morphology Unit, School of Dental Science, Universiti Sains Malaysia, Kelantan, Malaysia \\ (Accepted for publication, April 28, 2016)
}

\begin{abstract}
The purpose of this study was to describe the morphology and measure the size of the sella turcica in Iraqi population and compared with available global data. Computed Tomography (CT) images of 71 individuals (49 males and 22 females) with an age range of 33.9 years were taken. Conventional measurements included three different heights of the sella turcica (anterior, posterior, median), its length, diameter and width, measured in relation to the Frankfort reference line $(\mathrm{FH})$. In addition, the area of sella turcica was calculated. Morphometric methods were used to assess shape. Multiple statistical analyses were done to calculate differences in dimensions and to establish if any relationship exists between age, sex and the morphometry of the sella turcica. No significant differences in size of the sella were found between genders. When age was evaluated, all dimensions showed positive correlation with the age. Sella size of the older age group was as a rule larger than the younger age. The study found that sella turcica presented with a three different shapes: in a U shape $(50.7 \%)$, in a J shape $(32.4$ $\%)$ and shallow (16.9\%). Sella shape and dimensions reported in the current study can be used for discovering pathological enlargement of the pituitary fossa and may also be helpful in providing reference data in the orthodontic diagnosis, assessment and treatment plan and assessment of racial, gender and age specific variation in the Iraqi population.
\end{abstract}

Key words: Morphometry, CT, Sella turcica size, Morphology.

\section{Introduction}

Sella turcica consists of a central pituitary fossa bounded anteriorly by tuberculum sellae and posteriorly by dorsum sellae. It is located in the middle cranial fossa and lies on the intracranial surface of the body of the sphenoid bone and project over the pituitary fossa two anterior and two posterior clinoid processes. The anterior clinoid processes are formed by the medial and anterior prolongations of the lesser wing of the sphenoid bone, and the terminations of dorsum sellae are present in the form of posterior clinoid processes ${ }^{1)}$.

Previous studies focus on size and morphology of sella turcica. A normal anatomical variation of the sella turcica must be considered, as it may vary significantly in normal adult individuals ${ }^{2)}$.

Sella turcica acts as a significant reference point and important

Correspondence to: Dr. Haider Ali Hasan, Dr. Mohammad Khursheed Alam, School of Dental Science, Universiti Sains Malaysia. Kubang Kerian 16150, Kota Bharu, Kelantan, Malaysia; Tel: 6097675811, 60188714479 ; Fax: 607642026; E-mail addresses: alshammari79@yahoo.com; dralam@gmail.com landmark can be seen on lateral cephalograms. It is obvious for metric analysis, which makes it an excellent source of information related to various syndromes that affect the craniofacial region and the identification of pathologies of pituitary gland. Knowledge of the normal radiological anatomy and variations in the morphometry of this area are helpful as a tool to evaluate the orthodontic treatment results, to study growth in an individual, and to recognize and further investigate a variety of pathological situations $^{3-5)}$.

The anatomy of the sella turcica is varies in size and shape, and has been classified into three types: round, oval and flat ${ }^{6)}$. According to previous studies, the normal range of the sella turcica varies between $11-16 \mathrm{~mm}$ in length and $8-12 \mathrm{~mm}$ in routine bilateral $\mathrm{x}$-ray film of skulls ${ }^{7}$. Bergland et al. studied the sella turcica in connection with 225 autopsies and found 6 percent with a sella turcica bridge by direct inspection. They classified the sella turcica into three segments; an anterior wall (the tuberculum sellae), the floor and the posterior wall (the dorsum sellae) ${ }^{8}$.

Traditionally, cephalometric tracing is performed on a lateral 
J.Hard Tissue Biology Vol. 25(3): 227- 232, 2016

Table 1. Definition of landmarks

\begin{tabular}{cll}
\hline Landmark & Name & \multicolumn{1}{c}{ Definition } \\
\hline TS & Tuberculum Sella & The most anterior point of the contour of the sella turcica \\
DS & Dorsum Sellae & The posterior wall of the sella turcica \\
SF & Sella Floor & The deepest point on the floor of pituitary fossa \\
PClin & Posterior Clinoid & The most anterior point of the PClin process \\
SA & Sella Anterior & The most anterior point of the sella \\
SP & Sella Posterior & The most posterior point of the sella \\
SM & Sella Medium & A point midway between PClin and TS \\
FH & Frankfort Plane & Is traced from Porion (Po): The most superior point on the \\
& & upper rim of the external auditory meatus to Orbitale (Or): \\
& & The most inferior point on the lower rim of the orbit \\
\hline
\end{tabular}

cephalogram, a technique that was first introduced by Hofrath, 1931 in Germany and Broadbent, 1931 in the United States ${ }^{9-10)}$. This technique was widely accepted as a standard tool for orthodontic treatment planning for several decades. However, it has shown several disadvantages because of the geometric distortion and superimposition of structures on the radiographs.

Recently, three-dimensional (3D) imaging modalities such as $\mathrm{CT}$ and cone-beam computed tomography (CBCT) have played an important role in dentistry. $\mathrm{CBCT}$ requires relatively lower radiation doses than multi-slice $\mathrm{CT}$, and has therefore become very popular for maxillofacial diagnosis and treatment planning. The orthodontists are able to visualize 3D images of craniofacial structures without involving the superimposition of anatomical structures ${ }^{11-12)}$. This modality has proven to be useful in several orthodontic applications, including 3D cephalometry.

$3 \mathrm{D}$ cephalometry offers orthodontists the opportunity to identify cephalometric landmarks in three dimensions with the aid of 3D image viewing software ${ }^{13,14}$. According to several studies, this technique has advantages over traditional twodimensional (2D) cephalometric analysis, especially on the accuracy of the measurements and the reproducibility of landmark identification $^{15)}$.

It is imperative to know the normal morphology of the sella turcica in order to determine if the sella region presents with any unusual appearance. Morphology may vary from individual to individual, and the establishment of normal standards will aid in the process of eliminating any abnormality in such an important region. Therefore, the purposes of our study are as follow:

1. To determine sex related morphological shape and size of the sella turcica in the Iraqi population.

2. To determine age related morphological shape and size of the sella turcica in the Iraqi population.

3. To compare the morphological size of sella turcica of the present study with global data.

\section{Materials and Methods}

\section{Subjects}

A retrospective study of Iraqi subjects who had their CT scan at the Radiology Department, Hilla Hospital has been conducted. Patients had their scans for reasons other than craniofacial surgeries. CT scans of 71 individuals (49 males and 22 females) with an age range of 1 - 70 years were taken.

All participants provide their written informed consent (One of the parents, either father and/or mother gave written consent for the adolescent subjects). This study was approved by the Ethical Committee of the Hilla Hospital, which complies with the Declaration of Helsinki. The data were divided into two groups according to the subject's age: pre-pubertal ( $<15$ years) and post pubertal (15 years or more). It has been accounted for that the morphology of sella turcica does not change impressively following 12 years of age ${ }^{16)}$ and females at roughly 15 years old have completed their pubertal development; sella turcica size in young adult males and females have been accounted for to be practically the same,, except during pregnancy ${ }^{17}$.

The selection criteria are as follows.

1. Subjects with CT images and the presence of the sella turcica with maximum clarity.

2. All subjects were clinically healthy with no syndromes, clefts, or other craniofacial abnormalities either congenital, acquired through road traffic accidents or other forms of trauma and developmental discrepancies.

3. No significant pathology of the maxillofacial region.

4. No significant facial asymmetry.

5. No significant anatomical variation in the sella turcica and sphenoidal regions.

6. Patients using hormonal medications or corticosteroids were excluded from the study.

\section{CT imaging}

CT images were collected from a CT database of Hilla Hospital. These scans were of high resolution, helical scans obtained with General Electric (GE) Light Speed Plus CT Scanner System (GE company, Medical system group, Wisconsin, USA). 
Haider Ali Hasan et al.: 3DCT Morphometric analysis of Sella Turcica

Table 2. Comparisons of sella turcica measurements between male and female subjects.

\begin{tabular}{lllccc}
\hline \multicolumn{7}{c}{ Mean $(\mathrm{SD})$ distance $(\mathrm{mm})$} & \multicolumn{2}{c}{ 95\% Confidence Interval } & \\
\hline Variables & Male & Female & Lower Bound & Upper Bound & P value \\
\hline TS-PClin & $8.46(1.61)$ & $8.42(2.32)$ & -0.91 & 0.98 & 0.93 \\
SA-SP & $8.21(1.60)$ & $8.21(1.73)$ & -0.83 & 0.85 & 0.98 \\
TS-DS & $10.79(2.28)$ & $10.47(2.01)$ & -0.81 & 1.44 & 0.58 \\
TS-SF & $7.41(1.80)$ & $6.81(1.05)$ & -0.22 & 1.42 & 0.15 \\
PClin-SF & $7.40(1.43)$ & $7.03(1.49)$ & -0.37 & 1.10 & 0.32 \\
SM-SF & $7.44(1.34)$ & $7.07(1.22)$ & -0.29 & 1.04 & 0.27 \\
TS-SA-SF- & $65.29(21.81)$ & $60.33(21.44)$ & -6.15 & 1.60 & 0.37 \\
SP- PClin & & & & & \\
\hline
\end{tabular}

Table 3. Pearson's coefficient of correlation in age vs. sella turcica dimensions.

\begin{tabular}{lcl}
\hline & Age & \\
\hline Variables & $\mathrm{r}$ & P value \\
\hline TS-PClin & 0.58 & $0.02 *$ \\
SA-SP & 0.73 & $<0.001 * * *$ \\
TS-DS & 0.75 & $<0.001 * * *$ \\
TS-SF & 0.50 & $0.06^{*}$ \\
PClin-SF & 0.69 & $0.03 *$ \\
SM-SF & 0.57 & $<0.001 * * *$ \\
TS-SA-SF-SP- PClin & 0.55 & $<0.001 * * *$ \\
\hline
\end{tabular}

Table 4. Global and current study data regarding sella turcica measurements.

\begin{tabular}{|c|c|c|c|c|c|c|c|c|c|c|}
\hline Measurement & Unit & current & Greece $^{25}$ & Saudi & Pakistan ${ }^{26)}$ & Brasil $^{21)}$ & $\operatorname{Iran}^{27)}$ & India $^{28)}$ & Nigeria ${ }^{29)}$ & Turkey ${ }^{30)}$ \\
\hline & & & & Arabia $^{18)}$ & & & & & & \\
\hline Instrument & & $\mathrm{a}$ & $\mathrm{b}$ & $\mathrm{b}$ & $\mathrm{b}$ & $\mathrm{a}$ & $\mathrm{b}$ & $\mathrm{b}$ & $\mathrm{c}$ & $\mathrm{b}$ \\
\hline No. subjects & & 71 & 184 & 180 & 180 & 100 & 90 & 180 & 100 & 118 \\
\hline Sella length & $\mathrm{mm}$ & 8.46 & 7.1 & 11 & 11.4 & 10.31 & 9.04 & 8.8 & 12.59 & $\times$ \\
\hline Sella width & $\mathrm{mm}$ & 8.21 & 8.9 & $\times$ & $\times$ & $x$ & $\times$ & $\times$ & $\times$ & 11.1 \\
\hline Sella diameter & $\mathrm{mm}$ & 10.79 & $\times$ & 13.9 & 13.9 & $\times$ & 13.02 & 10.9 & $x$ & 14.1 \\
\hline Sella height anterior & $\mathrm{mm}$ & 7.41 & 6.7 & $\times$ & $\times$ & $\times$ & $\times$ & $\times$ & $x$ & $\times$ \\
\hline Sella height posterior & $\mathrm{mm}$ & 7.40 & 6.6 & $\times$ & $\times$ & $\times$ & $\times$ & $\times$ & $\times$ & $\times$ \\
\hline Sella height median & $\mathrm{mm}$ & 7.44 & 6.6 & 9.1 & 9.8 & 6.33 & 8.03 & 7.1 & 8.94 & 9.3 \\
\hline Sella area & $\mathrm{mm}$ & 65.29 & 46.1 & $\times$ & $\times$ & 41.21 & $\times$ & $\times$ & $\times$ & $\times$ \\
\hline
\end{tabular}

Instrument used for data collection: (a) CT; (b) Cephalometry; (c) lateral X-rays.

The CT resolution was at $1.25 \mathrm{~mm}$ thickness and $1.25 \mathrm{~mm}$ spacing. These scans were saved in a CT database at the Radiology Department of Hilla Hospital.

\section{$3 D$ Reconstruction}

CT scans were saved in Digital Imaging and Communications in Medicine (DICOM) format, then was transferred to a personal computer, and reconstructed with a 3D image-segmentation program, Mimics V17.0 software (Materialise N.V., Heverlee, Belgium). This software uses the existing axial view to create cross-sections in the sagittal and frontal views. The Hounsfield Unit (HU), which expresses the gray scale, was adjusted for each tissue in the CT system.

\section{Measurements}

3D image-segmentation using Mimics software program was used to carefully select seven points and seven parameters from the identified landmark points. Table 1 lists the landmarks used in this study and Fig. 1 showed the parameters defined using the above mentioned landmark points. A single operator did all the measurements. All linear and area measurements were repeated 3 times. After the first measurements were completed, the results were blinded to the observer before trying the second measurements. The same blinding was done when the observer 
Table 5. Frequency distribution of sella turcica type.

\begin{tabular}{lcc}
\hline Sella type & Frequency & Percentage \\
\hline U shape & 36 & 50.7 \\
J shape & 23 & 32.4 \\
Flat & 12 & 16.9 \\
\hline
\end{tabular}

measured for the third time. The blinding was done to minimize the examiner's bias. The average of three readings of each measurement was considered for the final statistical analysis in order to minimize the intra-examiner variation.

\section{Statistical analyses}

All data were analyzed using SPSS software 22.0 (IBM, Armonk, NY, USA). The normality of the data was evaluated with the skewness and kurtosis measurements. General descriptive statistics were calculated for each parameter. A Student's $t$-test was used to calculate the mean differences in sella turcica linear and area dimensions between males and females while the correlation between the sella turcica dimensions and age was investigated using Pearson's correlation coefficient, Statistical significance was set at $\mathrm{p}<0.05$.

\section{Results}

\section{Size of the sella turcica}

The linear and area dimensions of the sella turcica located in the mid sagittal plane area are presented in Fig. 1. The average of three different heights of the sella turcica (anterior, posterior, median), its length, diameter and width, measured in relation to the FH. In addition, the area of sella turcica was calculated for both females and males are also shown in Fig. 1. When comparing linear dimensions of sella turcica between genders as in Table 2, no significant differences between females or males in all parameters could be found. Similarly, when linear and area dimensions were compared with age, there were no significant differences between the older and the younger age groups for all dimensions. It was noted that sella turcica in the older group was consistently larger than that in the younger age group as in Table 3. Moreover, When our measurements were compared with those in other global data, differences in all parameters among various populations were observed Table 4 .

\section{Shape of the sella turcica}

In respect of its shape, the sella turcica was radiologically shown as three different shapes: in a U shape (50.7\%), when the dorsum and tubercle of the sella turcica are maintained at the same height; in a $\mathrm{J}$ shape (32.4\%), when the sella turcica tubercle is in a lower position in relation to the dorsum; and shallow (16.9\%), when the sella turcica depth is minimum as in Table 5.

\section{Discussion}

Figure 1. Saggital view shows Sella turcica parameters: a. Sella diameter (TS-DS); b. Sella length (TS-Pclin); c. Sella height anterior (TS-SF); d. Sella height posterior (PClin-SF); e. Sella height median(SM-SF); f. Sella width (SA-SP); g. Sella area.

This retrospective study describes the morphological appearance, linear dimensions and area of the sella turcica in Iraqi healthy subjects. Measurements of the sella turcica and examination of its morphology are vital for the evaluation of pathology in the pitutary gland. Numerous scientists have been accounted for the shape variety in the sella turcica ${ }^{18)}$.

Many studies were reported on shape and size variations in the sella turcica ${ }^{19,20)}$. Ruiz et al. ${ }^{21)}$ examined the CT scans of adults $18-60$ years of age and classified the sella turcica into a $U$ shape, $\mathrm{J}$ shape, and flattened, or saucer shaped. According to the researches, it was concluded that most of the subjects had either a U or J-shaped sella. In our study, roughly most of the subjects seemed to have a typical molded sella turcica, while $32.4 \%$ gave distinctive aberrations. This is in concurrence with the data of Axelsson et al. ${ }^{22}$

No significant gender differences were found in determining the differences between males and females in terms of sella turcica size in the present study. Similar findings were reported by Alkofide $(2007)^{18)}$ who concluded that sella turcica size in young adult males and females were almost the same, although he noted that sella turcica size may increase in males with age. In that study, radiographs of 320 individuals, 1 month to 18 years of age, the mean sella area was calculated (length and depth). The findings revealed that the pituitary fossa of males tended to be larger than that of females from about 1-13 years of age ${ }^{18)}$. Females begins pubertal growth 2 years earlier than males, results in a significant change in pituitary fossa size in females from 11 to 15 years of age. Then, the late growth acceleration in males, which is usually $2-3$ years later than that in females, results in an approximate equalization in sella area in both genders Females begins pubertal growth 2 years earlier than males, results in a significant change in pituitary fossa size in females from 11 to 15 years of age. In contrast, Haas (1954) ${ }^{23)}$ compared the mean size in square millimetres of the sella area of boys and girls aged $3-17$ years and found some differences due to gender. He reported that the 
Haider Ali Hasan et al.: 3DCT Morphometric analysis of Sella Turcica

sella turcica of boys was greater than girls, but after 17 years of age, the sella of females were slightly larger than that of males ${ }^{23)}$.

Study done by Tejavathi et al. 2015 to assess the linear dimensions of sella turcica in different age groups. The patients were grouped into five different categories, $<10$ years, $10-15$ years, 15-20 years, 20-25 years, $25 \square 30$ years. There was difference in the linear measurements of depth, and anteroposterior diameter in each age group which increased as age increased and the difference was statistically significant with $P<0.05$. Choi et al. also reported that lin-ear dimensions of sella turcica had positive inclination with the age ${ }^{24)}$.

Based on the results of this study, gender differences were statistically insignificant for all linear and area measurements of sella turcica. There is a gradual increase in the size of sella turcica as age advances. The sella shape and size may be used as reference standards for Iraqi subjects when studying sella turcica morphology.

\section{Acknowledgment}

This study was suppoted by USM RUI Grant 1001/PPSG/ 812154 .

\section{Conflict of Interest}

The authors have declared that no COI exist.

\section{References}

1. Chauhan P, Kalra S, Mongia SM, Ali S and Anurag A. Morphometric analysis of sella turcica in North Indian population: A radiological study. Int J Res Med Sci 2:521526,2014

2. Camp JD. The normal and pathologic anatomy of the sella turcica as revealed by roentgenograms. Am J Roentogenol 12:143-156, 1924

3. Friedland B and Meazzini MC. Incidental finding of an enlarged sella turcica on a lateral cephalogram. Am J Orthod Dentofacial Orthop 110: 508-512, 1996

4. Feldkamp J, Santen R, Harms E, Aulich A, Mödder U and Scherbaum WA. Incidentally discovered pituitary lesions: high frequency of macro adenomas and hormone-secreting adenomas: results of a prospective study. Clin Endocrinol (Oxf) 51: 109-113, 1999

5. Alkofide E. Pituitary adenoma: A cephalometric finding. Am J Orthod Dentofacial Orthop 120: 559-562, 2001

6. Jones RM, Faqir A, Millet DT, Moos KF and McHugh S. Bridging and dimensions of sella turcica in subjects treated by surgical orthodontics means or orthodontics only. Angle Orthod 75: 714-718, 2004

7. Clucton LA, Dorst P and Garn SM. The volume of the sella turcica in children new standard. Am J Roentogenol 140: 797-801, 1983
8. Teal JS. Radiology of the sella turcica. Bull Los Angeles Neurol Soc 78: 451-460, 1977

9. Hofrath H. Bedeutung der Röntgenfern und Abstands Aufnahme für die Diagnostik der Kieferanomalien. Fortschr Orthod 1: 231-258, 1931

10. Broadbent BH. A new x-ray technique and its application to orthodontia. Angle Orthod 1: 45-66, 1931

11. Pauwels R, Beinsberger J, Collaert B, Theodorakou C, Rogers J, Walker A, Cockmartin L, Bosmans H, Jacobs R and Bogaerts R. Effective dose range for dental cone beam computed tomography scanners. Eur J Radiol 81: 267-271, 2012

12. van Vlijmen OJ, Kuijpers MA, Bergé SJ, Schols JG, Maal TJ, Breuning $\mathrm{H}$ and Kuijpers AM. Evidence supporting the use of cone-beam computed tomography in orthodontics. J Am Dent Assoc 143: 241-252, 2012

13. Swennen GR, Schutyser F, Barth EL, De Groeve P and De Mey A. A new method of 3-D cephalometry Part I: the anatomic Cartesian 3-D reference system. J Craniofac Surg 17: 314-325, 2006

14. Hasan HA, Alam MK, Yusof A, Matsuda S, Shoumura M and Osuga N. Accuracy of three dimensional CT craniofacial measurements using mimics and Invesalius software programs. J Hard Tissue Biolo 25: 219-224, 2016

15. Brown AA, Scarfe WC, Scheetz JP, Silveira AM and Farman AG. Linear accuracy of cone beam CT derived 3D images. Angle Orthod 79: 150-157, 2009

16. Kjaer I, Hansen N, Becktor KB, Birebaek N and Balslev T. Craniofacial morphology, dentition, and skeletal maturity in four siblings with Seckel syndrome. Cleft Palate Craniofac J 38: 645-651, 2001

17. Pisaneschi $M$ and Kapoor $G$. Imaging the sella and parasellar region. Neuroimaging Clin N Am 15: 203-219, 2005

18. Alkofide EA. The shape and size of the sella turcica in skeletal Class I, Class II, and Class III Saudi subjects. Eur J Orthod 29: 457-463, 2007

19. Kantor ML and Norton LA. Normal radiographic anatomy and common anomalies seen in cephalometric films. Am J Orthod Dentofacial Orthop 91: 414-426, 1987

20. Tetradis S and Kantor ML. Prevalence of skeletal and dental anomalies and normal variants seen in cephalometric and other radiographs of orthodontic patients. Am J Orthod Dentofacial Orthop 116: 572-577, 1999

21. Ruiz CR, Wafae N and Wafae GC. Sella turcica morphometry using computed tomography. Eur J Anat 12: 47-50, 2008

22. Axelsson S, Storhaug K and Kjær I. Post-natal size and morphology of the sella turcica. Longitudinal cephalometric standards for Norwegians between 6 and 21 years of age. Eur J Orthod 26: 597-604, 2004

23. Choi WJ, Hwang EH and Lee SR. The study of shape and 
size of nor-mal sella turcica in cephalometric radiographs. Korean J Oral Maxillofacial Radiol 31(1): 43-49, 2001

24. Nagaraj T, Shruthi R, James L, Keerthi I, Balraj L and Goswami RD. The size and morphology of sella turcica: A lateral cephalometric study. J Med Radiol Pathol Surg 1: 3-7, 2015

25. Andredaki M, Koumantanou A, Dorotheou D and Halazonetis J. A cephalometric morphometric study of the sella turcica. Eur J Orthod 29: 449-456, 2007

26. Shah AM, Bashir U and Ilyas T. The shape and size of the sella turcica in skeletal class I, II \& III in patients presenting at Islamic International Dental Hospital, Islamabad. Pakistan Oral Dent J 31: 104-110, 2011

27. Valizadeh S, Shahbeig S, Mohseni S, Azimi F and
Bakhshandeh H. Correlation of Shape and Size of Sella Turcica with the Type of Facial Skeletal Class in an Iranian Group. Iran J Radiol 12: 1-7, 2015

28. Sathyanarayana HP, Kailasam V and Chitharanjan AB. The size and morphology of sella turcica in different skeletal pattern among South Indian population. A lateral cephalometric study. J Ind Ortho Soc 47: 266-271, 2013

29. Osunwoke EA, Mokwe CR and Amah-Tariah FS. Radiologic measurements of the sella turcica in an adult Nigerian population. Int J Clin Pharmacol Res 4: 115-117, 2014

30. Marsan G and Öztş E. Incidence of bridging and dimensions of sella turcica in class I and III Turkish adult female patients. World J Orthod 10: 99-103, 2009 